MANAGEMENT ISSUES IN
HEALTHCARE SYSTEM
www.AIMIJOURNAL.COM

\title{
The relationship between job stress and turnover intentions in the pesticide sector of Pakistan: An employee behavior perspective
}

\author{
Syeda Sania Zahra, Muhammad Imran Khan, Muhammad Imran*, Qaiser Aman, \\ Rafaqet Ali
}

Department of Management Sciences, COMSATS Institute of Information Technology, VEHARI Campus

\begin{abstract}
\section{Keywords:}

Job Stress, Turnover Intentions, Work Overload, Supervisory Support, Work Ambiguity, Pesticide sector, Pakistan

Correspondence: imran@ciitvehari.edu.pk

The study outlines that stress exists in any ailing or unpleasing situation. Current study tries to uncover the relationship among work overload, work ambiguity and supervisory support, and employee turnover intentions. The twelve companies are selected out of 23 totals so the findings can be generalized on this sector. A structured questionnaire was distributed among the sample that consisted of 412 employees of this sector. Quantitative techniques were used to measure the results and statistical analyses were applied to confirm the research hypothesis. The findings of this study suggest that there is a significant and positive relationship between job stressors and employees' turnover intention. The job factors, relationships at work, and career development opportunities have also impact on employees' turnover intention. The job stress has a positive and significant impact on employees' turnover intention. Considering the importance of employees' turnover intention and job stress in Pesticide sector, the researchers and administrator and policy makers should take necessary measures to increase the supervisory support at work, minimize the work overload and work ambiguity, and improve other job factors to decrease the employees' intention to leave the organization.
\end{abstract}

CAIMI Journals

\section{Introduction}

The current thesis investigates how the work-related stress impacts the employees' turnover intention experienced by the employees of pesticide sector, using a sample of 410 working employees from ten pesticides' companies in Vehari district. The study provides a comprehensive examination of the nature and altitude of stress and turnover intention among 
employees and investigates the complex relationship between job stress and employee's turnover intention. In the present day the industries face an intense competition in market and they continuously manage the ways to survive. So, the human resource is a foundation to get an elevated pose in the market through their performance, efficiency, and fidelity to the organization. The employees suffer encumber or load of works sometimes in such a competitive and firm environment of the organization. This milieu generates stress among employees that occurs from various reasons and directs to the intention to leave the organization. Stress is actually a mental or physical state that arises when a person feels something going against his/her thinking or feelings. The factors such as intricacy, workload, and an increase in responsibility are the causes which lead to stress. These factors are also known as stressors and they always have depressing and demolishing impact on employees' performance and productivity (Qasim, Javed, \& Shafi, 2014).

Stress is a component of every human existence and a human faces a sequence of stress in his everyday life. It becomes threat when a person faces it at work; so, it becomes an essential concern for the employer and the employees as well. There are many theories and different definitions about stress as it is very difficult topic to address and the level of stress vary from one person to another and the same person reacts differently in the same situation and different persons react the same in different situations. The author defined stress as psychological and physiological state that occurs in a certain environment. Stress arises when a person feels pressure and tension or any other negative feeling such as anxiety or anger (Joseph, 2013).

The success of an organization highly depends upon its employees. If there is the risk of quitting intention of employees, then the organization will have long lasting effects of this big challenge. High turnover becomes a loss for organization's cost and profitability (Hassan, 2014). Khan, Aqeel, and Riaz (2014) noted that when a person suffers from mental and physical illness because of the unwanted settings, the situation is known as stressed. He also noted that there are many types of stressors, namely noise, dim light at working place, high job demands, role overload, role ambiguity, lack of sleep and time pressure, and everyday workload, contradictory demands, insufficient resources to perform well, inability to make decisions, and conflicts. All these dimensions of stress direct to the dissatisfaction, meager health, and high job stress. Pakistan is a developing country and depends on its agriculture. Following this, $70 \%$ of its population is engaged with agriculture and give a large part of the national income. Pesticide sector is considered as a backbone in agriculture and Punjab is famous for its agriculture as most of the population is engaged with this profession and the employees of pesticides' sector always remain busy to develop and introduce new and effective products for the fields and farms. Most of the employees in this sector work in field and deals with the farmers. This sector has an impact on human, food commodities, and environment and on economy as well. The preceding studies on turnover have focused on the unlike factors causing turnover and then tackle the issues of how to retain the employees so the turnover rate may reduce. The organizations depleted a high cost of retaining the employees. The previous studies also categorize the diverse factors that impinge on the turnover. Current literature shows that there is an ample and mounting source of information regarding job stress and turnover. Rather than examining the undeviating impact of stress on employee turnover, a good reason is to find or check the impact of stress on the intention to leave the organization. 
The study outlines that stress exists in any ailing or unpleasing situation. Moreover, the study suggests that multiple dimensions of stress (known as stressors) identified by the researchers and some of these dimensions are work demands, job factors, role ambiguity, job insecurity, career development, time pressure, work overload, role conflict, lack of recognition, unclear requirements, biological or demographic variables can also become the cause of stress, leadership, personality, environment of the organization and relationship with others at work and many other dimensions as well.

The objectives of the study include understanding the nature of job stress and finding out the impact of a set of job stressors such as work overload, work ambiguity, and supervisory support on employees' turnover intention in pesticide sector of Pakistan.

\section{Stress}

Many theories have been developed by different researchers for stress over many years and these theories provide different frameworks to understand the stress and its different features or dimensions. All these theories have a common characteristic that it explains stress as "an active and powerful process functioning between an individual and his/her environment". There are some factors which create stress such as increasing level of education, work and life balance, work environment, marital status, financial constraint, job insecurity, lack of control, and poor time management. These certain factors are associated with intention to quit (Mxenge, DyWili, \& Bazana, 2014). Greenberg and Baron (2008) defined stress as a model which is composed of emotional and psychological states or reactions which happen to reply a requirement inside or outside the organization. Subsequently these demands become stressors which direct to the reaction of stress because the demands and situations go beyond one's control and become threaten. So, the job stress is the consequence of inequality between one's hopes and real situations at work. In other words, it is definite as the divergence between the professional demands and individuals' ability to clutch them out.

Kundaragi and Kadakol (2015) defined stress as a gap between the environment and persons' match and an interaction between situation and individual. Stress arises when the individual does not cope with the situations and pressure of demands and environment. Stress varies from individual to individual and situation to situation. Human being reacts both physically and mentally towards stress; for instance, if a person feels a situation negatively it will create stress in his/her mind while a person does not get stressed if he/she feels a situation positively. Othman, Lamin, and Othman (2014) carried out a research on occupational stress index. He states that stress arises when the demands of work feel to be uncontrolled and the employees cannot cope with it. Workloads impact on employees' wellbeing, time, and vigor as well. As the masses increase, the employees become unable to balance between mental and physical health and personal or impersonal issues. Other stressors are long working hours, interpersonal conflicts, workplace environments, motivation, employment status, job demand, job control, and participation in decision making. All of these stressors have a negative impact on employees' turnover intention.

Hwang et al. (2014) studied the collision of occupational stress on employees' turnover. Stress is an actually a physical and psychological state that arises in quite a lot of situations and can be viewed as a crucial part of a person. He tries to demonstrate, in the light of literature, that stress has a negative impact on employees' personal lives. As the stress decreases the 
productivity, self-esteem and performance of the employees also decrease. He studied hotel segment as turnover because stress is high in this segment. The principal component factor analysis is applied to measure the results. It is examined that employees who are affected by the occupational stress have intention to change their jobs. And turnover intention is considered as an interpreter of genuine turnover. The turnover intentions are high as the stress level is high. Stress arises from different sources and factors such as tribulations related to home, task, pay, and unfair treatment, inconsistency with job conscientiousness, organizational culture, and lack of support.

\section{Work Overload}

Some factors are there which is very unique to job such as workload, autonomy, mismatch, lack of training, and physical work environment. When the employees face long hours to work and no flexibility in working style or time, then they feel an overload of work: The situation is known as role overload or work overload. Keshavarza and Mohammadi (2011) worked to determine the factors of organizational stress and its impact on organizational performance. Role ambiguity and role conflict are also associated with satisfaction, absenteeism, expectations, involvement and tasks; all of these are low motivators and causes tensions. They also affect the performance and productivity of an organization. Role conflict arises when an employee interacts with colleagues and they have conflicting expectations about his/her behavior: While role ambiguity arises when an employee is not clear about what is being expected from him at work. In both situations, the stress arises. HRM practices also lead to stress such as recruiting, downsizing, and feedback. He also noticed many job stressors including help from coworkers, poor work environment, and participation in decision making, physical conditions of working such as noise, pollution, friendly policies, and support from supervisors. All of them have negative effect on employees' job. These stressors also affect the employees' health and satisfaction which causes a decrease in organizational performance and productivity. Naharuddin and Sadegi (2013) worked on employee's performance and stress. Qureshi et al. (2012) reported that there is a positive relationship between stress and turnover and the same relation is with work load and work environment. He used three variables, namely work load, job stress, and work environment to find their impact on employee's turnover intention. Many studies have attempted to answer the question that "which reasons lead the employees to quit the organization?". Othman et al. (2014) investigated the occupational stress index. He states that stress arises when the demands of work require to be uncontrolled and the employees cannot cope with it. Workloads impact on employees' well-being, era, and vigor as well. As the loads increases the employees become unable to balance between mental and physical health and personal or impersonal issues. Other stressors are long working hours, interpersonal conflicts, workplace environments, motivation, employment status, job demand, job control, and participation in decision making. All of these stressors have a negative impact on employees' turnover intention. Regarding the purpose, the researcher collected data from the government university in Malaysia through an OSI questionnaire and "weighted the components fairly and summed them to yield features of either under load, high demand, strictness, external time pressure, aversive physical exposures, symbolic of aversive and conflict or uncertainty". Researcher concluded that every employee has a different capacity and ideas to handle stressful situations. Stress varies from work to work and worker to worker. 
Solution for a problem can be positive for one employee but can be negative for other. Yang Liu, Lie, and zhang (2015) noted that the turnover rate becomes high due to work overload, complex work relationships, lack of career development opportunities, and long hours to work. He also considered that in America, Canada and Australia, the turnover rate among nurses is becoming high day by day due to such factors. To this end, there is a need to determine these factors to eliminate the threat of turnover among employees in all sectors. There is a strong correlation between retention and employee-driven career growth with the employees' job satisfaction.

\section{Supervisory Support}

Butali, Wesang'ula, and Mamuli (2013) stated that human resource professionals in an organization always remain busy to retain their employees to reduce turnover rate. He describes turnover as a term that is being used when an employer loses existing employees and then employs new ones to uphold those places. The human resource policies can create an efficient, loyal, and satisfied workforce. Turnover also has negative effects on an organization's performance, efficiency, fertility and competencies. The turnover of the staff is not just the concern for the organization itself but also for those organizations who converse with them. It becomes intricate to maintain a fine relationship with those organizations that have a high employee turnover rate. They both face the results of staff turnover.

\section{Work Ambiguity}

Many authors worked on different factors. Hundera (2014) stated that the stress arises due to the mismatch between expectations and an individual who does not have apparent information related to the techniques and procedures to accomplish the task. So the performance of the employees gets low; this situation is known as role ambiguity or the work ambiguity. Hangyue, Foley, and Loi (2005) defined that ambiguity arises when there are no clear standards, and job descriptions are vague and not specified in the organization. So the situation leads an employee to quit the job and search for a new one. The higher the role ambiguity is, the lower the job satisfaction and job performance will be; while the higher ambiguity means the greater propensity to leave the job. Duygulu, Ciraklar, Guripek, and Bagiran (2013) noted that in different studies (organizational, psychological and sociological), the role stress has received a lot of attention. He examined two main role stressors, namely role conflict and role ambiguity. Role stress has a variety of outcomes for the employees as well as organization such as anxiety, tension, high turnover, absenteeism, and impact on physical health. Stress also decreases the performance, productivity, satisfaction and commitment. Especially role conflict and role ambiguity directly affect the level of satisfaction and employees' physical health. Stress also influences the employees' well-being at work. The researchers' focus is to examine the relationship among the employees' well-being and job stressors. In this regard, it is also stated that stress affects an employees' mental and physical health that causes organizational outcomes such as turnover. He defined that ambiguity arises when an employee is less aware of his/her role in the organization and have no or few information being expected from them. As the ambiguity increases the job satisfaction, performance decreases, and the anxiety also increases which directly affects the employees' intentions to stay or exit the job. The findings 
of this research show the direct and positive effect of ambiguity on intention to quit (Loi, 2005).

\section{Turnover Intention}

Turnover refers to a kind of behavior which explains the procedures of leaving or replacing employees in an organization (Currivan, 1999). In management, turnover is not new but an important issue in human resource management which attracts the interest of public administration and industrial relations management practitioners all over the world. As the competition increases, the organizations must develop strategies to retain the employees (Ongori, 2007). Bothma and Roodt (2013) stated that turnover intention is very much studied and validate but there is need to validate the turnover intention scale (TIS). Turnover is a planned behavior to leave the organization. It is also noted that turnover is a deliberate intention or a part of an employee's strategy to escape from the current situation. There is an indirect relationship between turnover and job demands. When there are a lot of job demands, the stress arises and leads to turnover intentions. The job resource also stimulates the turnover intentions. Turnover is dependent on many personal and impersonal reasons and a person leaves the job when he/she finds another job easily or he/she has other opportunities. The quitting intention has always a high cost and negative outcomes. Kumar and Govindarajo (2014) stated that there are a few instruments available in literature to measure some of the concepts such as absenteeism, turnover, and retention. There are some factors that make the decision easy to say whether the employees will stay or leave such as rewards, fairness at workplace, bullying and harassment, poor management relationships, management support, supervisor, safety and security, coworker relationship and others as well. The researcher used qualitative techniques to identify those factors which enforce the employees to stay or leave. Following this, the factor analysis is also used. According to Varshney (2014), turnover can be defined as the members who quit the organization for those opportunities which they considered more suitable than their current jobs. Employees who leave the organization by their own choice or by the requests of others, both creates troubles for the organization. The organization bears a loss of investment which they do in training and selection of such employees. The turnover is the outcome of the attitudes and behaviors of coworkers and supervisors on job and in every state of affairs the intention of quitting becomes dependent on different factors, and turnover becomes an opposite dependent variable to predict the actual intentions of quitting. As the intention to quit is increased, the turnover also increases.

Varshney (2014) focused on the theory of self-concept to explain more variety in employees' turnover. The personality traits enable the researchers to perk up comprehending the reasons of turnover and the collision of every attribute on it. Following this, she proposed that individual level of self-concept is positively and the collective level of self-concept is negatively associated with the turnover intent. The turnover intention is an individual intention to quit not only the location but also the job, role, and work environment. 


\section{Research Hypotheses}

The following hypotheses guided the study:

$\mathbf{H}_{1}$ : There exists a positive relationship between work overload and employees' turnover intention.

$\mathbf{H}_{\mathbf{2}}$ : There exists a positive relationship between supervisory support and employees' turnover intention.

$\mathbf{H}_{3}$ : There exists a positive relationship between work ambiguity and employees' turnover intention.

Figure 1 illustrates the research model and hypothesis.

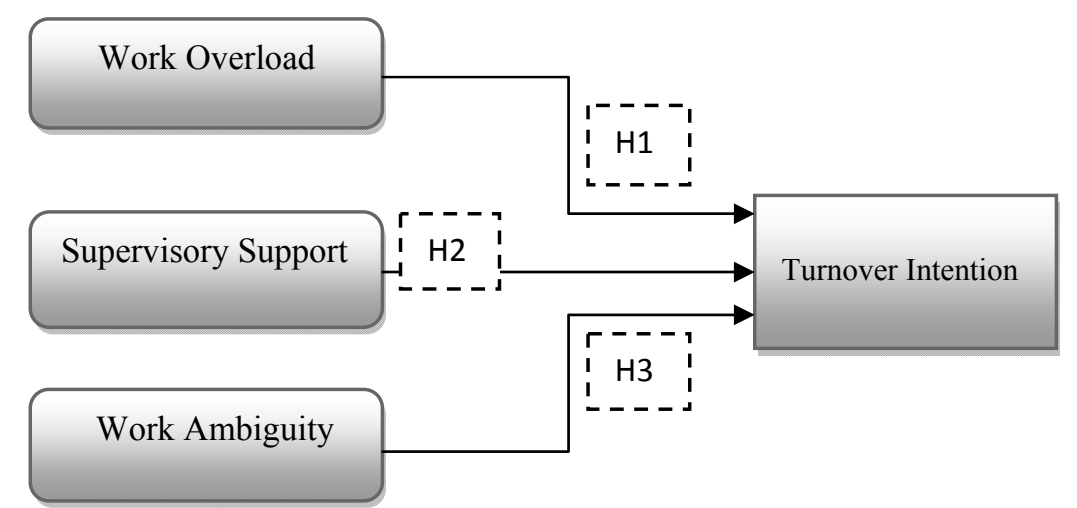

Figure 1. Research model and hypotheses

\section{Method}

The existing study is exploratory in nature and the quantitative techniques are used. A structured questionnaire approach is used to measure the results and find out the role of stressors. There are twenty-three generic companies in Vehari District and the ten companies are selected to fill the questionnaire on the basis of some factors, namely their market shares, sales, and growth. The population size includes all the employees working in the selected companies and the sample is selected from this population. The information about the companies is gathered from the district office of agriculture, Vehari.

The sample size is determined with the help of book by Sekaran and Bougie (2010). Firstly, the normality of all variables has been tested and then the Pearson correlation and regression and descriptive statistics have been applied on the data. The purpose of using these tests is to analyze the effect of independent variables on the dependent variable that is turnover intention. The researchers consider the age, education, and marital status of the employees because these factors also play their roles in creating stress.

Out of the total sample, $97.8 \%$ of the employees are male, under age of $25-34$, approximately $67.5 \%$ are married while $32.5 \%$ are single and mostly on low scale of education.

Table 1 shows the demographic characteristics.

\section{Measurements of Variables}

The researcher used different scales to measure the results. All the responses are measured at five point response scale. The five points scale include $1=$ never, $2=$ seldom, $3=$ sometimes, $4=$ often, and 5=always. All the variables are coded in software to find out the results such as 
male $=1$ and $2=$ female; married $=1$, unmarried $=2$, and others $=3$. Education is coded as masters $=1$, bachelors $=2$, intermediate $=3$, matric $=4$ and middle/primary $=5$. The ages of the employees are coded as $1=$ under $25,2=25$ to $34,3=35$ to $44,4=45$ to 54 , and 5=55-64. A structured questionnaire (items are adopted on each variable) is distributed among the selected sample. The sample size of 412 are taken from the selected companies in Vehari, all the responses are received at the rate of $100 \%$ response rate; in that sample 97.8 percent represents the ratio of male and 2.2 percent represents that ratio of female employees. Data was analyzed using SPSS software.

Table 1

Demographic Characteristics

\begin{tabular}{lccc}
\hline Variable & Category & Frequency & Percentage \\
\hline \multirow{2}{*}{ Gender } & Male & 403 & 97.8 \\
& Female & 009 & 2.2 \\
& Under 25 & 45 & 10.9 \\
\multirow{3}{*}{ Age } & $25-34$ & 149 & 36.2 \\
& $35-44$ & 143 & 34.7 \\
& $45-56$ & 69 & 16.7 \\
& $55-64$ & 6 & 1.5 \\
\multirow{2}{*}{ Education } & Masters & 125 & 30.3 \\
& Bachelors & 110 & 26.7 \\
& Intermediate & 127 & 30.8 \\
\multirow{2}{*}{ Marital Status } & Matric & 34 & 8.3 \\
& Middle/Primary & 16 & 3.9 \\
\hline
\end{tabular}

The items of the questionnaire are adopted from different authors. Table 2 represents the description of the variables and the items with the source of the information. There is a larger part of job factors and then there are some items on relationships at work, career development opportunities, and then turnover intention.

Table 2

Description of the Variables

\begin{tabular}{|c|c|c|}
\hline Variable & Item & Source of Information \\
\hline $\begin{array}{l}\text { Supervisory Support } \\
\text { Work Ambiguity }\end{array}$ & $\begin{array}{l}\text { I am pressured to work long hours. } \\
\text { I have unachievable deadlines. } \\
\text { I have to work very fast. } \\
\text { I have to neglect some tasks because I have too much to do } \\
\text { I am unable to take sufficient breaks } \\
\text { My working time can be flexible } \\
\text { I am given supportive } \\
\text { feedback on the work I do } \\
\text { I can rely on my manager to help me out with a work problem } \\
\text { I am supported through emotionally demanding work. } \\
\text { My line manager encourages me at work. } \\
\text { When changes are made at work, I am clear how they will work out in practice } \\
\text { I am clear what is expected of me at work. } \\
\text { I am clear about the goals and objectives for my department } \\
\text { I know how to go about getting my job done. } \\
\text { I am clear what my duties and responsibilities are. }\end{array}$ & Cousins, et al. (2004) \\
\hline Turnover Intention & $\begin{array}{l}\text { I often think about quitting. } \\
\text { It is likely that I will actively look for new job next year. } \\
\text { I will probably look for a new job in the next year. } \\
\text { I often think of changing my job. }\end{array}$ & Sheraz, et al. (2014) \\
\hline
\end{tabular}




\section{Results}

Table 3 represents the model summary and regression coefficients " $R$ " $=0.39$ or $39.4 \%$ which means that association between dependent variable (turnover intention) and independent variables (work ambiguity, work overload, and supervisory support) is affirmative. The coefficient of determination " $\mathrm{R}$ " $=0.15$ shows that $15.5 \%$ of variation in turnover intention is explained by independent variables.

Table 3

Model Summary

\begin{tabular}{lllll}
\hline Model & $\mathrm{R}$ & $\mathrm{R}$ Square & Adjusted R Square & Std. Error of the Estimate \\
\hline$\underline{\mathbf{1}}$ & $0.39^{\mathrm{a}}$ & 0.15 & 0.14 & 0.96 \\
\hline
\end{tabular}

a. Predictors: (Constant), WA, WO, SRS

Table 4 (ANOVA) describes that there is one model being reported. Three categories including regression, residual, and total are examined through the variance in the outcome and explained by the variable. The total variance is explained in two parts of variance; variance explained by independent variables and the variance not explained by the independent variable. Degree of freedom is denoted by df. The total variance has $\mathrm{N}-1$ degrees of freedom. Including the intercept, there are 4 coefficients so the model has $4-1=3$ degrees of freedom. The error degrees of freedom are the df total minus df model $400-3=397$.

Table 4

\begin{tabular}{lccccc} 
ANOVA $^{\mathrm{b}}$ & \multicolumn{1}{c}{} & & \\
\hline Model & Sum of Squares & df & Mean Square & F & Sig. \\
\hline Regression & 69.03 & 3 & 23.01 & 24.47 & $0.00^{\mathrm{a}}$ \\
Residual & 376.07 & 400 & 0.94 & & \\
Total & 445.10 & 403 & & & \\
\hline
\end{tabular}

a. Predictors: (Constant), WA, WO, SRS

b. Dependent Variable: TOI

For ANOVA Table the null hypothesis states that the population means are equal. So, we use a significance level of 0.05 to evaluate the null hypothesis and 0.05 significance levels demonstrates $5 \%$ risk which concludes that a difference exists when there is no actual difference. The null hypothesis is rejected because the sig. is 0.00 which is less than 0.05 and it is concluded that not all of the population means are equal. Following this, it is also concluded that all variables have different means and all the three independent variables are related to employees' turnover intention.

The F-test value is 24.74 which is significant because the significance level is 0.00 that is less than 0.05 ; therefore, the null hypothesis is rejected and alternative hypothesis will be accepted that is turnover intention is confidently connected with work overload, work ambiguity, and supervisory support. This also implies that the correlation between dependent variable and independent variables is statistically significant and the regression model is valid. The valid regression model implies that all independent variables, namely job factors, career development opportunities, and relationships at work explain that there is a positive and significant relationship between turnover intentions (dependent variable).

Table 5 represents the coefficients. In Table 5 , the regression coefficient for work overload is $\beta^{1}=0.21$ which implies that one percent increase in work overload increases 0.21 percent 
turnover intention if other variables are kept under control. The t-test value is positive which is 4.54 and significant at 0.00 because significance level is less than .05 . The regression coefficient is $\beta^{2}=-.16 .2$ which implies that one percent increase in supervisory support brings on the average $16.2 \%$ decrease in employees' turnover intention if other variables remain constant. The t-test value is -2.46 and statistically significant at 0.01 levels which is less than 0.05. It implies that the relationship between SRS and turnover intention is negative and significant. The relationship is significant and the model is valid. The regression coefficient is $\beta^{3}=-0.19$ or $19.5 \%$ which implies that one percent increase in work ambiguity brings on the average $19.5 \%$ decrease in turnover intention if other variables are constant. The t-test value is -2.97 and statistically significant $(0.00)$ at significance level $(0.05)$.

Table 5

Coefficients $^{a}$

\begin{tabular}{|c|c|c|c|c|c|c|c|}
\hline \multirow{2}{*}{ Model } & \multicolumn{2}{|c|}{ Unstandardized Coefficient } & \multirow{2}{*}{$\begin{array}{c}\begin{array}{c}\text { Standardized } \\
\text { Coefficient }\end{array} \\
\text { Beta }\end{array}$} & \multirow{2}{*}{$\mathrm{t}$} & \multirow{2}{*}{ Sig. } & \multicolumn{2}{|c|}{$95 \%$ Confidence Interval for B } \\
\hline & B & Std. Error & & & & Lower Bound & Upper Bound \\
\hline 1 (Constant) & 3.34 & 0.27 & & 12.21 & 0.00 & 2.80 & 3.87 \\
\hline WO & 0.29 & 0.06 & 0.21 & 4.54 & 0.00 & 0.167 & 0.42 \\
\hline SRS & -0.20 & 0.08 & -0.16 & -2.46 & 0.01 & -0.36 & -0.04 \\
\hline WA & -0.22 & 0.07 & -0.19 & -2.97 & 0.00 & -0.37 & -0.07 \\
\hline
\end{tabular}

a. Dependent Variable: TOI

Table 6 shows the behavior of the data through the correlations. The study finds out the Pearson Correlation between Turnover Intention, Work Overload, and Supervisory Support, and Work Ambiguity. The correlation value lies between -1 and +1 . To this end, -1 represents the weak and negative relationship, while +1 represents perfect relationships between variables.

Table 6

Correlations

\begin{tabular}{lccccc}
\hline & & TOI & WO & SRS & WA \\
\hline \multirow{3}{*}{ Pearson } & TOI & 1.00 & .215 & -0.30 & -0.30 \\
Correlation & WO & 0.21 & 1.00 & -0.04 & 0.00 \\
& SRS & -0.30 & -0.04 & 1.00 & 0.71 \\
& WA & -0.30 & 0.00 & 0.71 & 1.00 \\
Sig. (1-tailed) & TOI & - & 0.00 & 0.00 & 0.00 \\
& WO & 0.00 & - & - & 0.43 \\
& SRS & 0.00 & 0.18 & 0.00 & 0.00 \\
N & WA & 0.00 & 0.43 & 404 & 404 \\
& TOI & 404 & 404 & 404 & 404 \\
& WO & 404 & 404 & 404 & 404 \\
\hline
\end{tabular}

The correlation matrix in Table 6 demonstrates the relationship between dependent and independent variables. The analysis show that there is high level of correlation between these variables at 0.05 significance levels. The Pearson Correlation between Turnover Intention (TOI) and Work Overload (WO) is positive and statistically significant which means that there is a strong correlation between these variables. The value 0.21 shows that the correlation is significant at 0.05 levels. In the same way, the Pearson Correlation between Supervisor Support (SRS) and Turnover Intention (TOI) is negative between these variables. The value -0.30 indicates that the correlation is insignificant at 0.05 level. The value 0.18 is not less than $p<0.05$ 
which means that the null hypothesis will be accepted and the alternate hypothesis will be rejected which indicates supervisory support and turnover intention is not much associated with one another.

The Pearson Correlation between Work Ambiguity (WA) and Turnover Intention (TOI) is also negative which means there is a weak relationship between these variables. The value 0.30 proves that the correlation is insignificant at 0.05 levels. The value 0.43 is greater than $p$ or $\mathrm{p}>0.05$.

The descriptive statistics, correlation, and regression analysis are functional to validate the results. All the results are consistent with the literature review.

\section{Discussion and Conclusion}

This study is a first attempt to represent the impact of job stress on employees' turnover intention in Pesticide Sector. Several hypotheses have been proposed and all of them are discussed separately. Although the literature shows the adverse effect of turnover in many organizations, this study also provides evidence that this relationship affects the pesticide sector in this region. The study also fills the research gap and enhances the perceptive to understand the relation of turnover intention and work stress in general. Furthermore, it donates to the literature by including the conceptual framework for the relationship between job stress and intentions to leave. This impact has not been fully investigated in previous research in the same context and this study tests it empirically. It is concluded that job stress has an impact on employees' turnover intentions. The results are also consistent with the previous work.

The research provides deep insight to the researcher and practitioners in this filed to look into the collision of job stressors on employees' turnover intentions and provide the guideline or baseline for the enhancement of different job factors, skills, supervisory support, and work overload. The research is also source of secondary data for the researchers working in this field who are interested to study the effects of stress in other dimensions on the employees' turnover intention.

Although the results are valuable but the limitations must be taken into account. Firstly, this study considered a few job stressors such as career opportunities, relationships at work, and other job factors including working hours, working environment, loads of work, and managers' help. Results of this study will make available the information on the subject of the Employees' Turnover Intention and the problems practiced by the Pesticide Sector of Vehari District for researchers and policy makers. This research may only be considered as an exploratory research to explore the observable fact of turnover intention in this sector. It is anticipated that this study will be the forward motion for researchers to conduct research in same settings using different variables to check the impact of job stress on employees' intention to leave. Existing market drifts in this area may be different from the drifts of other cities and this result will change the aims of employees. Major respondents of our study are males and turnover intention of males varies from turnover intention of females. Results will be different if respondents will be from different cities and countries because intentions fluctuate from society to society. In addition, the result will be different if there is a large number of females. Reproduction of the results in future studies would provide affirmation of the relationship under exploration. 


\section{References}

Bothma, C. F., \& Roodt, G. (2013). The validation of the turnover intention scale. SA Journal of Human Resource Management, 11(1), 1-12.

Butali, N. D., Wesang'ula, P. M., \& Mamuli, L. C. (2013). Factors causing staff turnover at Masinde Muliro University of Science and Technology. Greener Journal of Socail Sciences, 3(1), 067-074.

Currivan, D. B. (1999). The causal order of job satisfaction and organisational commitment in models of employee turnover. Human Resource Management Review, 9(4), 495-524.

Duygulu, E., Ciraklar, N. H., Guripek, E., \& Bagiran, D. (2013). The Effect of Role Stress on the Employee's Well-being: A Study in the Pharmaceutical Companies in the City of Izmir. Procedia-Social and Behavioral Sciences, 84, 1361-1368.

Greenberg, J. \& Baron, R. A. (2008). Behaviour in organizations. Upper Saddle River, New Jersey: Pearson-Prentice hall.

Hang-yue, N., Foley, S. \& Loi, R. (2005, Novemebr). Work role stressors and turnover intentions: A study of professional clergy in Hong Kong. The International Journal of Human Resource Management, 16(11), 2133-2146.

Hassan, R. (2014). Factors influencing turnover intention among technical employees in Information Technology Organization: A case of XYZ (M) SDN. BHD. International Journal of Arts \& Commerce, 3(9), 120-137.

Hundera, M. B. (2014). Factors affecting academic staff turnover intentions and the moderating effect of gender. International Journal of Research in Business Management (IMPACT: IJRBM), 2(9), 57-70.

Hwang, J., Lee, J. J., Park, S., Chang, H. \& Kim, S. S. (2014). The impact of occupational stress on employee's turnover intention in the luxury hotel segment. International Journal of Hospitality \& Tourism, 15, 60-77.

Joseph, T. D. (2013). Work related stress. European Journal of Business \& Social Sciences, 1(10), 73-80.

Keshavarza, M., \& Mohammadi, R. (2011). Occupational stress and organizational performance, case study: Iran. Procedia Social \& Behavioral Sciences, 30, 390-394.

Khan, E. A., Aqeel, M., \& Riaz, M. A. (2014). Impact of job stress on job attitudes and life satisfaction in college lecturers. International Journal of Information \& Education Technology, 4(3), 370-373.

Kumar, D., \& Govindarajo, N. S. (2014). Instrument Development “Intention to Stay Instrument” (ISI). Asian Social Science, 10(12), 149-169.

Kundaragi, P. B., \& Kadakol, A.M. (2015). Work stress of employee: A literature review. International Journal of Advance Research \& Innovative Ideas in Education, 1(3), 18-23.

Mxenge, S. V., DyWili, M., \& Bazana. S. (2014). Organizational stress and employees' intention to quit amongst administrative personnel at the University of Fort Hare, Eastern Cape, South Africa. International Journal of Research in Social Sciences, 4(5), 13-29.

Naharuddin, N.M. \& Sadegi, M. (2013). Factors of workplace environment that affect employees performance: a case study of Miyazu Malaysia. International Journal of Independent Research \& Studies, 2(2), 66-78.

Ongori, H. (2007). A review of the literature on employee turnover. African Journal of Business Management, 1(3), 49-54.

Othman, C. N., Lamin, R. A. C., \& Othman, N. (2014). Occupational stress index of Malaysian university workplace. Procedia - Social \& Behavioral Sciences, 153, 700-710.

Qasim, T., Javed, U., \& Shafi, M. S. (2014). Impact of stressors on turnover intention: Examining the role of employee wellbeing. International Journal of Social, Behavioral, Educational, Economic \& Management Engineering, 8(1), 181-189.

Qureshi, M. I., Jamil, R.A., Iftikhar, M., Arif, S., Lodhi, S., Naseem, I., \& Zaman, K. (2012). Job stress, workload, environment and employees turnover intentions: Destiny or choice. Archives of Sciences, 65(8), 230-241.

Sekaran, U., \& Bougie, R. (2010). Research methods for business: A skill building approach (5 ${ }^{\text {th }}$ ed.). Chichester: John Wiley $\&$ Sons.

Sheraz, A., Wajid, M., Sajid, M., Qureshi, W. H., \& Ramzan, M. (2014). Antecedents of job stress and its impact on employee's job satisfaction and turnover intentions. International Journal of Learning \& Development, 4(2), $204-226$.

Varshney, D. D. (2014). Impact of self-concept on turnover intention: An empirical study. American International Journal of Contemporary Research, 4(10), 87-96.

Yang, Y., Liu, Y. H., Liu, J. Y., \& Zhang, H. F. (2015). The impact of work support and organizational career growth on nurse turnover intention in China. International Journal of Nursing Sciences, 2(2), 134-139. 